\title{
An Inventory Policy for Discount only for the First Purchase
}

\author{
Suresha Kharvi* \\ Mangalore University \\ Mangalagangotri 574199, India
}

\author{
T. P. M. Pakkala \\ Mangalore University \\ Mangalagangotri 574199, India
}

\begin{abstract}
There are various discount strategies of the supplier to the retailer in the business filed. One of the common business discount strategy is the first-time buyer offer. This article considers an optimal inventory policy of the retailer for such discount strategy of the supplier. A finite horizon with constant demand is considered. A closed form solution to the optimal number of orders and optimal order quantities are obtained. Numerical example is considered to support theoretical results. Sensitivity analysis is carried out to find the effect of each parameter of the model on the optimal policy.
\end{abstract}

Keywords: Inventory, First purchase discount, optimal policy, optimal cost, Two-price problem.

\section{INTRODUCTION}

There are various discount strategies of the supplier to the retailer in the business filed. One of the common business discount strategy is the first-time buyer offer. Clearly provides all new buyers with a $50 \%$ discount for first purchase on prescription glasses. DODOcase, an online manufacturer of iPad cases, offers $10 \%$ off for the first purchase. WooCommerce also provides first order discount. The primary reason to provide discount for the first purchase is to attract new retailers. This will also help the supplier to clear the stocks.

In response to the first order discount of the supplier, the retailer has to develop an optimal inventory policy for a finite horizon. The retailer has to order more for the first order, since there is a discount. But for a given discount how large could be first order? It cannot be too large because in such case holding cost will be more. Another question that retailer needs to answer is how many numbers of orders to be placed? This paper answers both the questions by minimising the total cost. Yearly demand of the customers is assumed to be constant and known to the retailer. The above pricing strategy of the supplier results in two-price problem.

Purchase price change problem is one of the common problems in inventory management that has attracted the attention of many researchers. The pioneering work in this field was that of Naddor [10], who analysed an infinite horizon EOQ model following a price increase announcement made by the supplier. The EOQ model when purchase price change follows a straight line was studied by Goyal [5]. Buzacott [1] has studied the optimal ordering policy when price changes continuously due to inflation. An optimal ordering policy when information about price rise was known is developed by Lev and Soyster [8]. Goyal [4] provided an alternative method for determining the optimal policy for the model of Lev and Soyster [8]. Taylor and Bradley [12], extended Naddor's [10] model and found the optimal ordering strategies for situations where the price increase was to become effective at any specified future time. Lev and Wiess [9] also developed comprehensive model that covered both finite and infinite horizons under purchase price increase and decrease. Their algorithm for solving finite horizon EOQ model with price changes was modified by Andre Gascon [2]. An infinite horizon deterministic inventory model under an announced price increase was discussed by Ghosh [3], Huang and Kulkarni [6]. Taleizadeh and Pentico [11] developed EOQ model with a known price increase and partial back-ordering. The optimal inventory policy for price fluctuation due to the fluctuation of exchange rate is well addressed by Suresha Kharvi, T.P.M. Pakkala, and Srinivasan [7] in their article.

Even though there are many articles on price change problem, no attempt has been made to develop an optimal inventory policy for discount only for first purchase. The solution procedures used in earlier literatures to obtain optimal policy cannot be used for the problem discussed in this article and hence new solution procedure is used. The paper is organized as follows. Assumptions and Notations used in the article is considered in Section 2. The solution procedure to obtain the optimal number of orders, optimal order quantity and optimal cost of the model is presented in Section 3. In Section 4, numerical and sensitivity analysis is considered. Section 5 concludes the paper.

\section{ASSUMPTIONS AND NOTATIONS}

The following assumptions and notations are used in the article.

\section{a. Assumptions.}

1. Demand is constant;

2. Planning horizon is finite and known;

3. Shortages are not allowed;

4. Initial inventory is zero; and 


\section{Lead time is zero.}

\section{b. Notations}

Notations used in the article are:

c: Actual purchase price of the item.

$\mathrm{H}$ : Planning Horizon (in number of years)

$\alpha$ : Discount rate on the purchase price for first purchase of the retailer.

$\mathrm{R}$ : Demand for one year

K: Setup cost

F: Carrying cost fraction per unit amount of money per year

$\mathrm{n}$ : Total number of orders made after the first purchase.

\section{SOLUTION PROCEDURE}

Let $\mathrm{Q}_{\mathrm{D}}$ be the order quantity corresponding to first purchase. Let $\mathrm{Q}$ be quantity of items ordered by the retailer first purchase onwards. It is optimal to place the orders once the inventory level reaches zero. The retailer must answer two questions:

(i) Number of orders which needs to be placed during planning horizon

(ii) How much to order for the first purchase and first purchase onwards.

These two questions should be answered in a such a way that total cost of the inventory is minimum. The total cost of the inventory over the planning horizon $\mathrm{H}$ is given by

$$
\Psi_{n}\left(Q_{D}, Q\right)=(n+1) K+Q_{D} c \alpha+n c Q+\frac{Q_{D}^{2} c \alpha F}{2 R}+\frac{n Q^{2} c F}{2 R}
$$

The first term of RHS of (1) is the total set up cost. Since $(n+1)$ orders are placed with setup cost $K$, total setup cost is (n+1) K. Total cost for the items will be $Q_{D} c \alpha+n c Q$. Since during the first order cycle average inventory of $Q_{D} / 2$ is kept for the time of $Q_{D} / R$, holding cost for the first cycle is $\frac{Q_{D}^{2} c \alpha F}{2 R}$. For remaining $n$ orders holding cost will be $\frac{n Q^{2} c F}{2 R}$.

Since the total demand over the planning horizon $H$ is $R H, Q_{D}+n Q$ must be equal to $R H$. Hence $Q_{D}$ can be written as $Q_{D}=R_{H}-$ $\mathrm{nQ}$. By using the relation $\mathrm{Q}_{\mathrm{D}}=\mathrm{RH}-\mathrm{nQ}$, total cost can be expressed as a function $\emptyset_{n}($ ) of a single variable $\mathrm{Q}$.

i.e. $\emptyset_{n}(\mathrm{Q})=(\mathrm{n}+1) \mathrm{K}+(\mathrm{RH}-\mathrm{nQ}) \mathrm{c} \alpha+\mathrm{nQ} \mathrm{P}+\frac{(\mathrm{RH}-\mathrm{nQ})^{2} \mathrm{c} \alpha \mathrm{F}}{2 \mathrm{R}}+\frac{\mathrm{nQ}^{2} \mathrm{cF}}{2 \mathrm{R}}$

Optimal value of $\mathrm{Q}$ for given value of $\mathrm{n}$ is derived in the following theorem.

\section{Theorem 1:}

The Optimal order quantity after the purchase price for a given number of orders after the first purchase $\mathrm{n}$ is given by

$$
\mathrm{Q}_{\mathrm{n}}^{*}=\frac{\mathrm{R}}{\mathrm{F}}\left(\frac{\alpha(1+\mathrm{HF})-1}{1+n \alpha}\right)
$$

Proof: We have $\emptyset_{n}(\mathrm{Q})=(\mathrm{n}+1) \mathrm{K}+(\mathrm{RH}-\mathrm{nQ}) \mathrm{c} \alpha+\mathrm{nQ} \mathrm{c}+\frac{(\mathrm{RH}-\mathrm{nQ})^{2} \mathrm{c} \alpha \mathrm{F}}{2 \mathrm{R}}+\frac{\mathrm{nQ}^{2} \mathrm{cF}}{2 \mathrm{R}}$

First derivative of $\emptyset_{n}$ with respect to $\mathrm{Q}$ yileds:

$\frac{\mathrm{d} \emptyset_{n}}{\mathrm{dQ}}=-n \mathrm{c}(-1+\alpha+\alpha \mathrm{FH})+\frac{\mathrm{nQ} \mathrm{cF}(\mathrm{n}+\alpha)}{\mathrm{R}}$

Equating first derivative to zero and solving for $\mathrm{Q}$ results in $\mathrm{Q}=\frac{\mathrm{R}}{\mathrm{F}}\left(\frac{\alpha(1+\mathrm{HF})-1}{1+n \alpha}\right)$. Second derivative of $\emptyset_{n}$ with respect to $\mathrm{Q}$ is always positive. Hence optimal order quantity after the first purchase for the given value of $n$ is $Q_{n}^{*}=\frac{R}{F}\left(\frac{\alpha(1+H F)-1}{1+n \alpha}\right)$

Note that optimal order quantity after the first purchase depends on number of orders after the first purchase n, which also needs to be determine optimally. After the substitution of $Q_{n}^{*}$ for $Q$ in (2) optimal cost for given $n$, denoted by $\emptyset^{*}(n)$, can be found which is given by

$$
\emptyset^{*}(\mathrm{n})=(\mathrm{n}+1) \mathrm{K}+\mathrm{RHc} \alpha\left(1+\frac{\mathrm{FH}}{2}\right)-\frac{\mathrm{ncFL}^{2}}{2 \mathrm{R}(1+\mathrm{n} \alpha)}
$$

Where $\mathrm{L}=\frac{\mathrm{R}}{\mathrm{F}}(\alpha(1+\mathrm{HF})-1)$

It can be observed that once an optimal $n$ which minimises $\emptyset^{*}$ is found, optimal order qauntity after the first purchase and optimal cost can be found. Hence determination of optimal n needs special attention. Following properties of $\emptyset^{*}$ is useful to determine optimal $n$.

\section{Properties of the function $\emptyset^{*}()$ :}

1. If $1 \leq \frac{\mathrm{ncFL}^{2}}{2 \mathrm{R}(1+\mathrm{n} \alpha)}-\frac{1}{\alpha}$ then $\emptyset^{*}(0) \leq \emptyset^{*}(\mathrm{n})$ for $\mathrm{n} \geq 1$.

2. If $1>\frac{\mathrm{ncFL}^{2}}{2 \mathrm{R}(1+\mathrm{n} \alpha)}-\frac{1}{\alpha}$ then $\emptyset^{*}$ is a discrete convex function of $\mathrm{n}$.

From above property if $1 \leq \frac{\mathrm{ncFL}^{2}}{2 \mathrm{R}(1+\mathrm{n} \alpha)}-\frac{1}{\alpha}$ then 0 will be the optimal number of oders after the first purchase. Hence in such situation retailer must order $\mathrm{RH}$ units once with purchase price $\mathrm{c} \alpha$. If $1>\frac{\mathrm{ncFL}^{2}}{2 \mathrm{R}(1+\mathrm{n} \alpha)}-\frac{1}{\alpha}$ then optimal number of orders after the first purchase is not equal to 0 . In such case one, because of convex property of $\emptyset^{*}$ there will exists a unique optimal $n \geq 1$. Such $n$ can be 
determined using search procedure. But this may take more time when optimal $\mathrm{n}$ is large. Therefore determination of the closed form solution for $\mathrm{n}$ is required. Following theorem gives the optimal number of orders after the first purchase.

Theorem: The optimal number of orders after the first purchase is given by

$$
\mathrm{n} *=\left\lceil-\frac{1}{\alpha}-\frac{1}{2}+\sqrt{\frac{1}{4}+\frac{c_{2}}{\alpha^{2} k}}\right\rceil \text {, where }\lceil x\rceil \text { is the smallest integer greater than or equal to } \mathrm{x} \text {. }
$$

The proof of above theorem follows from the fact that $\emptyset^{*}$ is a convex function of $\mathrm{n}$, hence there exist a unique optimal $\mathrm{n} * \geq 1$ such that $\emptyset^{*}\left(n^{*}\right)<\emptyset^{*}\left(n^{*}-1\right), \emptyset^{*}\left(n^{*}\right)<\emptyset^{*}\left(n^{*}+1\right)$

$$
\mathrm{n}^{*}=\left[-\frac{1}{\alpha}-\frac{1}{2}+\sqrt{\frac{1}{4}+\frac{c_{2}}{\alpha^{2} k}}\right] \text { is only integer which satisfies (5). Once optimal number of orders after the first order is obtained }
$$

optimal order quantity and optimal cost can be obatined by subtituting

$$
\mathrm{n}=\left\lceil-\frac{1}{\alpha}-\frac{1}{2}+\sqrt{\frac{1}{4}+\frac{c_{2}}{\alpha^{2} k}}\right\rceil \text { in (3) and (4) respectively. Hence optimal order quantity after the first purchase is given by }
$$

$\mathrm{Q}^{*}=\frac{\mathrm{R}}{\mathrm{F}}\left(\frac{\alpha(1+\mathrm{HF})-1}{1+n^{*} \alpha}\right)$.

The optimal cost is $\emptyset^{*}\left(\mathrm{n}^{*}\right)=\left(n^{*}+1\right) \mathrm{K}+\mathrm{RHc} \alpha\left(1+\frac{\mathrm{FH}}{2}\right)-\frac{n^{*} \mathrm{cFL}^{2}}{2 \mathrm{R}(1+\mathrm{n} \alpha)}$.

Once $Q^{*}$ is obtained optimal $Q_{D}$ can be obtained using $Q_{D}^{*}=R H-n Q^{*}$.

\section{NUMERICAL EXAMPLE AND SENSITIVITY ANALYSIS}

To support theoretical results we considered numerical example with following parameters:

$\mathrm{c}=$ Rs . 100, $\mathrm{H}=5$ years, $\alpha=0.75$, $\mathrm{R}=1000, \mathrm{~K}=500, \mathrm{~F}=0.25$. An optimal solution obtained for these parameters is as follows: $\mathrm{n}^{*}=17, \mathrm{Q}^{*}=200$ units, $\mathrm{Q}_{\mathrm{D}}^{*}=1600$ units and $\emptyset^{*}\left(\mathrm{n}^{*}\right)=$ Rs. 501500.

According to the optimal policy the retailer has to order 1600 units for the first purchase and 200 units (17 times) next purchase onwards. The optimal number of orders over the planning horizon 5 years is 18 . The optimal cost is Rs. 501500. The convex property of function $\emptyset^{*}()$ with respect to the number of orders after the first purchase $n$ is displayed in the Fig 1.

Sensitivity analysis is carried out to idenify the effect of changes in the parameters on the optimal policy. In sensitivity analysis each parameters are chnaged by $-20 \%,-10 \%, 10 \%, 20 \%$ and other parameters are kept unchanged and are same as in the numerical example. Sensitivity analysis for all the parameters is considered in table 1 to table 6.

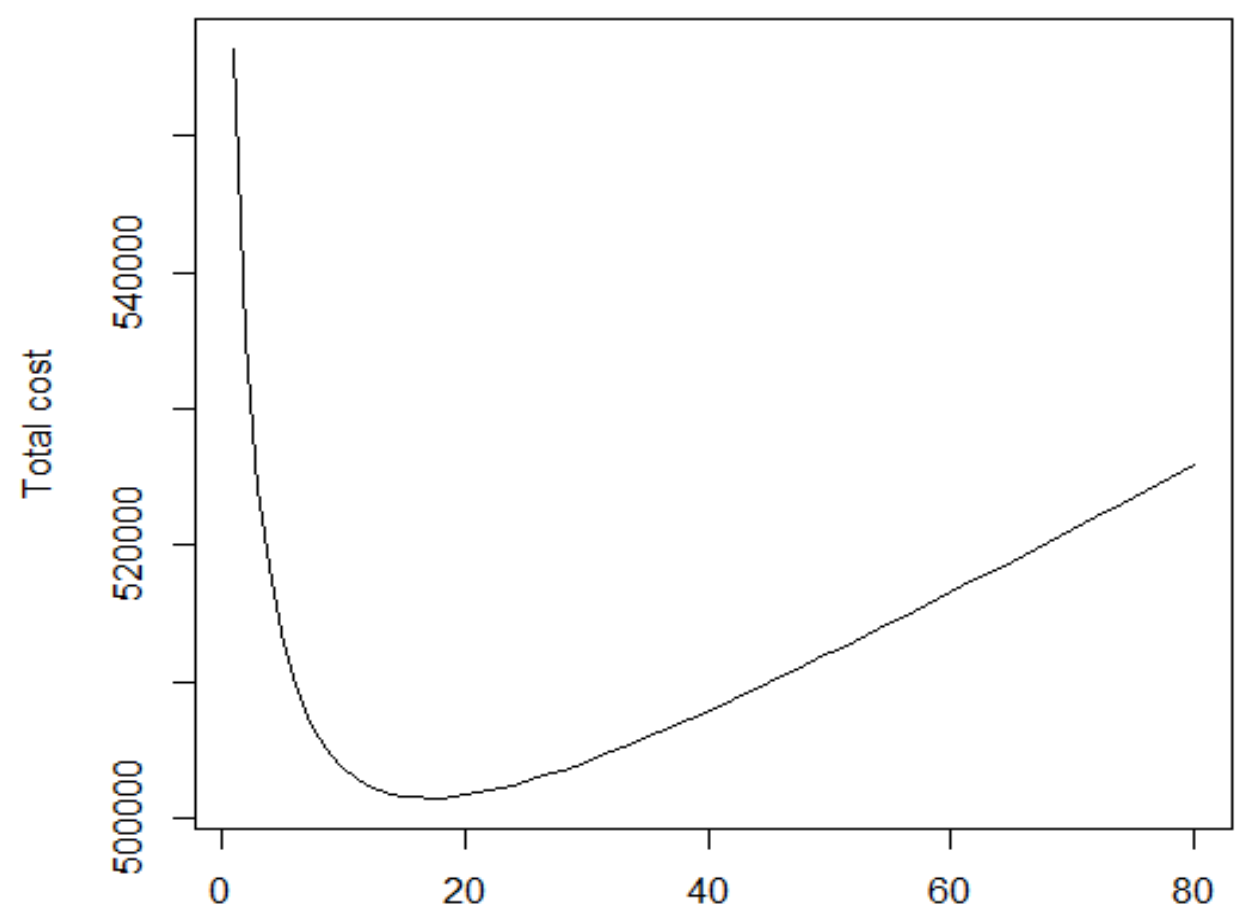

Number of orders after the first purchase

Fig. 1: Total cost vs optimal number of orders after the first purchase 
Table 1: Effect of change in c on optimal policy

\begin{tabular}{|c|c|c|c|c|c|}
\hline $\mathrm{c}$ & $\mathrm{n}^{*}$ & $\mathrm{Q}^{*}$ & $\mathrm{Q}_{\mathrm{D}}^{*}$ & $\emptyset^{*}\left(\mathrm{n}^{*}\right)$ & $\%$ Difference \\
\hline 80 & 15 & 224.4898 & 1632.6530 & 402898 & -19.6614 \\
\hline 90 & 16 & 211.5385 & 1615.3850 & 452226 & -9.8253 \\
\hline 100 & 17 & 200 & 1600 & 501500 & 0 \\
\hline 110 & 18 & 189.6552 & 1586.2070 & 550728.4 & 9.8162 \\
\hline 120 & 19 & 180.3279 & 1573.77 & 599918 & 19.6247 \\
\hline
\end{tabular}

Table 2: Effect of change in F on optimal policy

\begin{tabular}{|c|c|c|c|c|c|}
\hline $\mathrm{F}$ & $\mathrm{n}^{*}$ & $\mathrm{Q}^{*}$ & $\mathrm{Q}_{\mathrm{D}}^{*}$ & $\emptyset^{*}\left(\mathrm{n}^{*}\right)$ & \% Difference \\
\hline 0.2 & 14 & 217.3913 & 1956.5220 & 493913 & -1.5129 \\
\hline 0.225 & 15 & 215.4195 & 1768.7070 & 498008.5 & -0.6962 \\
\hline 0.25 & 17 & 200 & 1600 & 501500 & 0 \\
\hline 0.275 & 19 & 186.2891 & 1460.5070 & 504551 & 0.6084 \\
\hline 0.3 & 20 & 182.2917 & 1354.1670 & 507244.8 & 1.1455 \\
\hline
\end{tabular}

Table 3: Effect of change in $\mathrm{K}$ on optimal policy

\begin{tabular}{|c|c|c|c|c|c|}
\hline $\mathrm{K}$ & $\mathrm{n}^{*}$ & $\mathrm{Q}^{*}$ & $\mathrm{Q}_{\mathrm{D}}^{*}$ & $\emptyset^{*}\left(\mathrm{n}^{*}\right)$ & $\%$ Difference \\
\hline 400 & 19 & 180.3279 & 1573.7700 & 499598.4 & -0.3792 \\
\hline 450 & 18 & 189.6552 & 1586.2070 & 500575.9 & -0.1843 \\
\hline 500 & 17 & 200 & 1600 & 501500 & 0 \\
\hline 550 & 16 & 211.5385 & 1615.3850 & 502378.8 & 0.1752 \\
\hline 600 & 15 & 224.4898 & 1632.6530 & 503222.4 & 0.3434 \\
\hline
\end{tabular}

Table 4: Effect of change in R on optimal policy

\begin{tabular}{|c|c|c|c|c|c|}
\hline $\mathrm{R}$ & $\mathrm{n}^{*}$ & $\mathrm{Q}^{*}$ & $\mathrm{Q}_{\mathrm{D}}^{*}$ & $\emptyset^{*}\left(\mathrm{n}^{*}\right)$ & $\%$ Difference \\
\hline 800 & 15 & 179.5918 & 1306.1220 & 402898 & -19.6614 \\
\hline 900 & 16 & 190.3846 & 1453.8460 & 452226 & -9.8253 \\
\hline 1000 & 17 & 200 & 1600 & 501500 & 0 \\
\hline 1100 & 18 & 208.6207 & 1744.8280 & 550728.4 & 9.8162 \\
\hline 1200 & 19 & 216.3934 & 1888.5250 & 599918 & 19.6247 \\
\hline
\end{tabular}

Table 5: Effect of change in $\mathrm{H}$ on optimal policy

\begin{tabular}{|c|c|c|c|c|c|}
\hline $\mathrm{H}$ & $\mathrm{n}^{*}$ & $\mathrm{Q}^{*}$ & $\mathrm{Q}_{\mathrm{D}}^{*}$ & $\emptyset^{*}\left(\mathrm{n}^{*}\right)$ & \% Difference \\
\hline 4 & 12 & 200 & 1600 & 396500 & -20.9372 \\
\hline 4.5 & 15 & 193.8776 & 1591.8370 & 449007.7 & -10.4671 \\
\hline 5 & 17 & 200 & 1600 & 501500 & 0 \\
\hline 5.5 & 20 & 195.3125 & 1593.7500 & 554005.9 & 10.4698 \\
\hline 6 & 22 & 200 & 1600 & 606500 & 20.9372 \\
\hline
\end{tabular}

Table 6: Effect of change in $\alpha$ on optimal policy

\begin{tabular}{|c|c|c|c|c|c|}
\hline$\alpha$ & $\mathrm{n}^{*}$ & $\mathrm{Q}^{*}$ & $\mathrm{Q}_{\mathrm{D}}^{*}$ & $\emptyset^{*}\left(\mathrm{n}^{*}\right)$ & $\%$ Difference \\
\hline 0.6 & 10 & 200 & 3000 & 458000 & -8.6739 \\
\hline 0.675 & 14 & 198.5646 & 2220.0960 & 483833.7 & -3.5227 \\
\hline 0.75 & 17 & 200 & 1600 & 501500 & 0 \\
\hline 0.825 & 20 & 195.7143 & 1085.7140 & 513232.1 & 2.3394 \\
\hline 0.9 & 22 & 197.1154 & 663.4615 & 520502.4 & 3.7891 \\
\hline
\end{tabular}

Following observations are drawn from table 1 to table 6 .

(i) The setup cost have less impact on the optimal cost of the model among the parameters. As expected by the retailer increase ordering cost results in decrease in number of orders. When the setup cost is more the quantity to be ordered for the first and first purchase onwards both will be more.

(ii) Purchase price and Demand are highly sensitive to the optimal cost and they have same impact on the optimal cost.

(iii) As $\alpha$ increases optimal order quantity corresponding to the first purchase decreases.

(iv) Optimal number of orders increases with increase in the carrying cost fraction $\mathrm{F}$, since as $\mathrm{F}$ increase holding cost increases and hence it is better to order less quantity in order to have less holding cost.

\section{CONCLUSION}

This paper considers an optimal inventory policy of the retailer in response to first order discount offer by the supplier. Yearly demand of the customer is considered as constant and known to the retailer. A colsed form solution to the optimal number of orders and optimal order quantities is developed. The relation between first order quantity and discount price of the supplier is derived. Numerical example and sensitivity analysis is considered to highlight the important characteristic of the developed model.The model is also applicable for a situation where supplier mentions that this is the last chance for ordering in the present price and price increase will begin afterwards. 


\section{REFERENCES}

[1] Buzacott, J. A.: Economic Order Quantities with Inflation. Operational Research Ouarterly, 26(3), 553-558 (1975)

[2] Gascon, A.: On the Finite Horizon EOQ Model with cost changes. Operations Research, 43 (4), $716-717$ (1995)

[3] Ghosh A.K.: On some inventory models involving shortages under an announced. International Journal of Systems Science, 34(2), 129-137 (2003)

[4] Goyal, S. K.: A Note on the Paper: An Inventory Model with Finite Horizon and Price Changes. Journal of the Operational Research Society,30(9), $839-840(1980)$

[5] Goyal, S. K.: An Inventory Model for a Product for which Price Fluctuates. Operations Research, 3(2), 112-117 (1975)

[6] Huang, W., Kulkarni, V.G.: Optimal EOQ for announced price increases in infinite horizon. Operations Research, 51(2) ,336-339 (2003)

[7] Kharvi, S., Pakkala, T.P.M., Srinivasan, G.: Ordering policies under currency risk sharing agreements: a Markov chain approach. OPSEARCH, 56(3), 945-964 (2019)

[8] Lev, B., Soyster, A. L.: An Inventory Model with Finite Horizon and Price Changes. Journal of the Operational Research Society, 30(1), 43-53 (1979)

[9] Lev, B., Weiss, H.J.: Inventory Models with Cost Changes. Operations Research, 38(1), 53-63 (1990)

[10] Naddor, E.: Inventory systems. Wiley, New York (1966)

[11] Taleizadeh, A.A., Pentico, D.W.: An economic order quantity model with a known price increase and partial backordering. European Journal of Operational Research, 228(3), 516-525 (2013)

[12] Taylor, S.G., Bradley, C.E.: Optimal ordering strategies for announced price increases. Operations Research, 33(2), 312-325 (1985) 